\title{
Regulation of Heart Rate Variation by the Autonomic Nervous System in Neonatal Lambs
}

\author{
ANJA S. I. SIIMES, ILKKA A. T. VÄLIMÄKI, KARI J. ANTILA, MERVI K. A. JULKUNEN, \\ TAINA H. METSALA, LAURI T. HALKOLA, AND H. S. SAMULI SARAJAS \\ Cardiorespiratory Research Unit, University of Turku, Turku [A.S.I.S., I.A.T.V., K.J.A., T.H.M., L.T.H.]; \\ Departments of Physiology and Animal Hygiene, College of Veterinary Medicine, Helsinki [A.S.I.S., H.S.S.S.]; \\ and Departments I-II of Obstetrics and Gynecology, University of Helsinki, Helsinki, Finland [A.S.I.S., M.K.A.J.]
}

\begin{abstract}
We studied the role of the autonomic nervous system in the regulation of heart rate variation (HRV) in 12 chronically instrumented neonatal lambs. HRV was quantified from ECG tracings by computing periodic HRV distributions at frequencies of $0.02-1.00 \mathrm{~Hz}$, using power spectral analysis of heart rate, and also by HRV indices. Heart rate declined more during the 1st than the 2 nd mo after birth. Multiple regression analysis showed that the heart rate responses to vagal and to $\beta$-adrenergic blockade had an independent negative association both with age and with the initial mean heart rate, whereas the overall HRV response had a positive association with age. Vagal blockade led to a $70-80 \%$ decrease in the beat-to-beat HRV in all lambs $(p<0.001)$. The overall HRV indices decreased by $40-65 \%$ in lambs $(<30 \mathrm{~d}$ old $(p<0.001)$ and about $30 \%$ in those $>30 \mathrm{~d}$ old $(p<0.05)$. In the power spectrum the greatest decrease was seen in the high-frequency components of HRV. $\beta$-Blockade led to a decrease of about $50 \%$ in all HRV $(p<0.001)$ in the younger lambs, without frequency selection. In the older lambs, it had no effect on the beat-to-beat HRV, but the overall HRV (coefficient of variance) decreased maximally by $40 \%(p<0.01)$, with a significant reduction in the low-frequency components of HRV. These results suggest that in the regulation of HRV after birth dual control via the autonomic nervous system is most important. In the older lambs, developmental changes result in precise regulation of the fast heart rate fluctuations mainly by the vagal division, whereas the slow fluctuations are partially regulated by the vagal and $\beta$ adrenergic divisions. (Pediatr Res 27: 383-391, 1990)
\end{abstract}

\section{Abbreviations}

HRV, heart rate variation

RMSM, root mean square of differences from the mean interval, overall HRV

$\mathrm{CV}$, coefficient of variation for RMSM, relative overall HRV

RMSR, residual HRV (RMSM) after trend correction

CVR, coefficient of variation for RMSR, relative residual HRV

RMSSD, root mean square of successive interval differences, beat-to-beat HRV

CVS, coefficient of variation for RMSSD, relative beat-tobeat HRV

Received June 27, 1989; accepted December 11, 1989.

Reprint requests: Anja Siimes, M.D., Cardiorespiratory Research Unit, University of Turku, Kiinamyllynkatu 10, SF-20520, Turku, Finland.

Supported by grants from the Sigrid Juselius Foundation, the Academy of Finland, Turku University Foundation, and the Finnish Cultural Foundation.
Reduced HRV indicating altered cardiac control has been detected in neonatal respiratory disorders, particularly in newborns with respiratory distress syndrome (1-3), and in brain death (4). Further, infants subjected to birth asphyxia, and those who died of sudden infant death syndrome have been found to have exhibited low respiratory-related $\operatorname{HRV}(5,6)$. The mechanism of subnormal HRV in these cases is not known. HRV is also dependent on the maturity, age and sleep state of the neonate $(7,8)$. Inasmuch as $\mathrm{HRV}$ and particularly respiratory sinus arrhythmia are influenced by autonomic nervous system activity (9-12), we studied the HRV of lambs, because using spectral analysis no data are available on the relation of this activity to HRV during the neonatal period. We used spectral analysis and HRV indices and autonomic blocking agents to study the autonomic nervous control of HRV in lambs, because human neonates cannot for ethical reasons be experimentally manipulated.

\section{MATERIALS AND METHODS}

Experimental animals and surgical procedures. We studied 12 healthy full-term Finnish-breed newborn lambs. They were allowed a 3-d period of postnatal adaptation before surgery. They were housed with their mothers to allow normal lactation and not weaned before the end of the study. Pellets, which contained protein $14.5 \%$, and salt $0.5 \%$, and hay were added to their diet from the age of $3 \mathrm{wk}$. The growth of the lambs was normal during the study period.

Instrumentation was performed under local anesthesia with $1 \%$ lidocaine solution (8). Polyvinyl catheters filled with heparin solution and sealed with a metal plug were inserted into an external carotid artery and jugular vein. Bilateral silver ECG electrodes were implanted s.c. into the thoracic wall at the midaxillary line and tunneled to the neck of the animal. They were deposited with the catheters in a plastic pocket attached to the skin for the 10-wk study period. The animals were given parenteral gentamicin and penicillin for 3-4 d postoperatively. No recordings were done during this recovery period.

Signal acquisition and study protocol. During the 1-2 h recording periods the lambs were placed upright in a sling with freedom to sleep or stand comfortably in a quiet study room with an environmental temperature of 24 to $27^{\circ} \mathrm{C}$. Sequential recordings of ECG, heart rate, arterial blood pressure, and transthoracic electrical impedance respirograms were made using a Corometrics 512 Neonatal Monitor (Corometrics Medical System Inc., Wallingford, CT) and Statham pressure transducers. The signals were recorded continuously on paper and simultaneously stored on magnetic tape with an Analog 7 FM tape recorder (Philips) equipped with a storage monitor (Advance 2200, Advance, Essex, UK) for quality control. All recordings were made by one of the authors (A.S.I.S.), who documented the sleep state and motor activity of the lambs during the study sessions (8). 
The heart rate of the lambs decreased markedly with age, more during the 1 st than the 2 nd mo (Fig. 1). The break point (minimum residual variance) with two linear regression lines was at $30 \mathrm{~d}$. Therefore, the animals were divided into two subgroups, lambs $<30$ and $>30 \mathrm{~d}$ of age. Vagal blockade was induced with atropine sulfate injected as a bolus into the jugular vein at 0.1 or $0.2 \mathrm{mg} / \mathrm{kg}$ ( 15 and 21 experiments, respectively). The mean dose in the younger lambs was $0.15 \mathrm{mg} / \mathrm{kg}$ and in the older lambs $0.18 \mathrm{mg} / \mathrm{kg}$ (nonsignificant difference). $\beta$-Adrenergic sympathetic blockade was induced with a propranolol bolus at a dose of 1 or $2 \mathrm{mg} / \mathrm{kg}$ ( 16 and 10 experiments, respectively). The mean dose for the younger group was $1.2 \mathrm{mg} / \mathrm{kg}$ and for the older lambs $1.6 \mathrm{mg} / \mathrm{kg}$; there was no significant difference between the groups. All autonomic blockades were considered total, because no further change of heart rate could be produced by additional administration of the drugs.

The study protocol comprised a 30 -min control period and a 10 -min postdrug study period, during which a maximal $(90 \mathrm{~s})$ and a mean effect $(10 \mathrm{~min})$ of vagal or sympathetic blockade were documented. Arterial blood $\mathrm{pH}$ and gas tensions were measured before, $10 \mathrm{~min}$, and $1 \mathrm{~h}$ after the blockades were administered. One study, either with atropine or propranolol, was carried out each day (at most five blockade studies during the 10 -wk period) on one lamb. Inasmuch as the intervals between the experiments were long it was not considered necessary to randomize the order of the blockades.

Signal analysis. The R-R intervals were measured from the ECG and processed by a system consisting of two minicomputers (NOVA 3 and Eclipse C/150, Data General Corporation, Southboro, MA). During analogue preprocessing, correct $\mathrm{R}$ wave detection was verified visually with an oscilloscope. The timebase
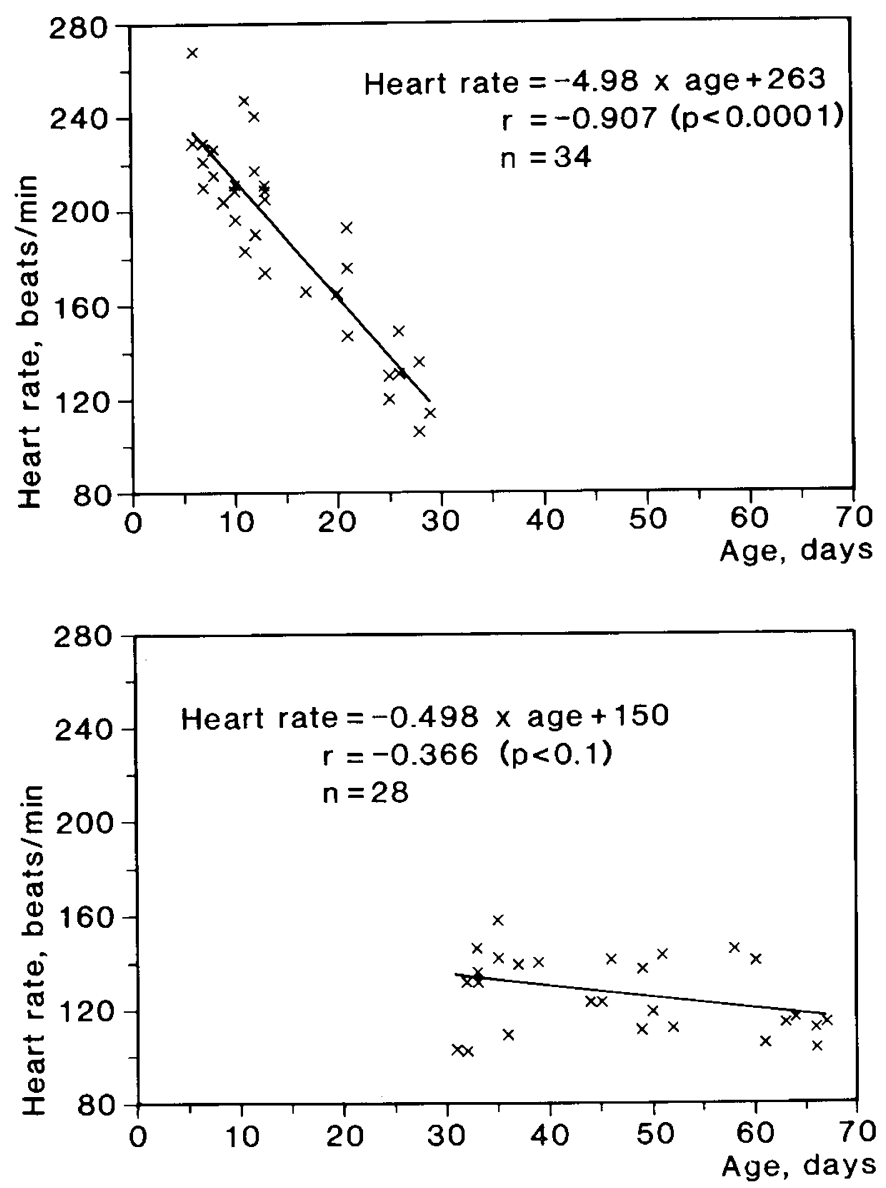

Fig. 1. Mean heart rate as a function of age of the animals, depicted using two linear regression analyses. The break point that yielded the best statistical difference (the least residual variance) between the two age groups was $30 \mathrm{~d}$. stability of the magnetic tape recorder was $0.6 \%$ including the triggering error. RMSM and RMSSD were computed for successive 90 -s periods of heart rate signal $(8,9)$ :

$$
\begin{array}{r}
\operatorname{RMSM}=\sqrt{1 / N \sum_{i=1}^{N}\left(R R_{i}-R R\right)^{2}, \text { and } R M S S D} \\
=\sqrt{1 /(N-1) \sum_{i=1}^{N-1}\left(R R_{i}-R R_{i+1}\right)^{2}}
\end{array}
$$

where $R R_{i}$ is the ith interval, $R R$ the mean $R-R$ interval, and $N$ the number of intervals in the sample. The corresponding coefficients of variation were used to estimate $\mathrm{HRV}$ in relation to the mean R-R interval: $\mathrm{CV}=100 \times \mathrm{RMSM} / \mathrm{RR}$, and $\mathrm{CVS}=$ $100 \times \mathrm{RMSSD} / \mathrm{RR}$. In addition, the R-R interval sequence was detrended by computing a 4 th order polynomial least-squares approximation and subtracting the polynomial trend from the signal to avoid the effect of slow trends on the HRV indices and any possible discontinuity between the break point of two successive $90-\mathrm{s}$ period signals. The overall residual HRV index computed for the detrended signal was called RMSR and the corresponding coefficient of variation CVR.

For power spectral analysis the R-R interval sequence was low-pass filtered and equispaced (sampling frequency $2.2 \mathrm{~Hz}$ ), using a $\sin (\mathrm{X}) / \mathrm{X}$ digital convolution filter. The signal was detrended using an up to 4th order polynomial approximation as described above. This detrending did not affect any data above $0.02 \mathrm{~Hz}$ in the power spectra of heart rate. The HRV power was computed for the frequency range of 0.0 to $1.0 \mathrm{~Hz}$, using a Fast Fourier Transformation algorithm. The individual HRV spectra, subdivided into 10 frequency bands, were band-integrated for intergroup comparisons $(8,10)$. Both the high-frequency and the low-frequency area were divided into five bands, of which the lowest band, $<0.02 \mathrm{~Hz}$, had no power after the trend correction (Figs. 3 and 5). The distribution of the power of HRV for each band was also computed in relative units, i.e. as percentages of the total area under the spectral curve. This relative bandintegrated HRV displayed the distribution of power within the spectral range and allowed a better comparison of records with high and low HRV.

Each animal served as its own control. Therefore, we compared heart rate and HRV values during control periods and blockades, using the paired $t$ test or the Wilcoxon test for paired observations. The latter test was used for comparison of power spectra. Differences between age groups were compared using the respective nonpaired tests. Linear and multiple regression analysis were used to correlate heart rate, HRV, and the change in heart rate and HRV during autonomic blockades with age and with the mean R-R interval or mean heart rate.

\section{RESULTS}

Arterial blood pressure and acid-base balance values of the lambs remained within normal limits during the experiments. The heart rate and HRV responses to the blockades were computed separately for each sleep state. Despite small differences in the distribution of HRV in the different sleep states, the mean responses were similar in each state. Therefore, they were pooled to assess the average response of heart rate and HRV variables to each blockade. However, the maximal HRV response was examined by comparing a 90 -s epoch at the maximal heart rate response with a control epoch in the same sleep state.

The heart rate versus age is depicted in Figure 1. Multiple regression analysis showed that the autonomic modulation of heart rate and HRV varied in relation to age and the mean heart rate or the mean R-R interval (Table 1). Either the mean R-R interval or the mean heart rate was used for analysis, whichever gave the better fit. RMSM, RMSR, and RMSSD showed positive associations with the mean R-R interval $(p<0.001)$. CV, CVR, and CVS were independent of the mean heart rate and the mean 
Table 1. Basal condition; regression analysis of $H R V$ related to age and to mean $R-R$ interval

RMSM $=-0.214^{0.03} \times$ age $+0.064^{0.001} \times$ mean R-R interval -0.33
RMSR $=-0.202^{0.04} \times$ age $+0.061^{0.001} \times$ mean R-R interval -1.70
$C V=-0.048^{0.03} \times$ age $+0.002^{\mathrm{NS}} \times$ mean R-R interval +5.55
CVR $=-0.045^{0.03} \times$ age $+0.003^{\mathrm{NS}} \times$ mean R-R interval +4.55
$\mathrm{RMSSD}=-0.210^{\mathrm{NS}} \times$ age $+0.084^{0.001} \times$ mean R-R interval -12.94
$\mathrm{CVS}=-0.041^{\mathrm{NS}} \times$ age $+0.100^{\mathrm{NS}} \times$ mean R-R interval +0.88

R-R interval. A negative association was observed between the age of the animals and the overall HRV, RMSM, RMSR, CV, and CVR $(p<0.05$, Table 1$)$. There was no such association between age and the beat-to-beat HRV.

Vagal Blockade. Heart rate and HRV indices. Examples of instantaneous heart rate tracings and transthoracic electrical impedance respirograms in two lambs before and after administration of atropine are shown in Figure 2. In response to vagal blockade there was an increase in heart rate and almost complete disappearance of visible "short-term" HRV. Especially in the older lamb, within a few minutes of administration of atropine, the heart rate underwent slow sinusoidal accelerations at the rate of $1-5$ oscillations/min (Fig. $2 B$ ).

The heart rate response to atropine had independent negative associations with both age and the mean heart rate of the lambs in multiple linear regression analysis $(p<0.001$; Table 2).

Vagal blockade led to a $41-65 \%$ reduction in the overall HRV indices $(p<0.001)$ in the $<30$-d-old lambs and to a $22-38 \%$ reduction in the older lambs $(p<0.05$; Table 3$)$. The reduction was greatest in the residual HRV (RMSR and CVR versus RMSM and CV, respectively, $p<0.001$ ). There was also an extensive reduction of $69-84 \%$ in the beat-to-beat HRV (RMSSD and CVS), which was independent of the age of the animals $(p<0.001$; Table 4$)$. The proportional changes in RMSM, RMSR, and CVR, which were unrelated to the mean $\mathrm{R}-\mathrm{R}$ interval or the mean heart rate, were age related $(p<0.05$; Table 2). However, there was no statistically significant difference in HRV between the two age groups (Table 4). The changes in $\mathrm{CV}$ and CVS were smaller than those in RMSM and RMSSD, respectively $(p<0.001)$.

The change in the maximal heart rate during vagal blockade was similar to the change in the average heart rate. Simultaneously, the overall HRV was $60-70 \%$ and the beat-to-beat HRV was $90 \%$ smaller than the respective indices for controls in the younger group ( $p<0.001$, data not shown). The respective values, were $50-60$ and $85 \%$ for the $>30$-day-old lambs $(p<$ 0.01 ).

Spectral components of $H R V$. In the younger lambs, the spectral density of HRV, depicted as the area under the spectral curve, decreased at the frequency $\geq 0.05 \mathrm{~Hz}$ during the first 10 min after atropine administration $(p<0.01$, Fig. $2 A)$. A similar reduction of $\mathrm{HRV}$ was found at frequencies of $>0.2 \mathrm{~Hz}(>12$ cycles/min) in the older lambs $(p<0.05-0.01$, Fig. $3 C)$, whereas the low-frequency HRV $(<0.1 \mathrm{~Hz})$ remained stable even though there was a systematic sinusoidal pattern of heart rate (Fig. 2). In both age groups, the percentage of low frequencies (less than six oscillations per min), measured as relative power density, increased. The relative spectral HRV power decreased at frequencies of $>0.1 \mathrm{~Hz}$ in the younger animals and at frequencies of $0.5-0.7 \mathrm{~Hz}$ in the older ones (Fig. $3 B$ and $D$ ). Results of spectral analysis of HRV during the maximal response of heart rate were similar to the mean responses during the 10-min analysis.

$\beta$-Adrenergic Blockade. Heart rate and HRV indices. Propranolol administration induced a $16 \%$ decrease in the average heart rate of the younger lambs $(p<0.001)$, which was smaller in the older lambs $(p<0.02$, Table 3 and 5; Fig. 4$)$. The heart rate change had a negative and independent association with both age and the mean heart rate (Table 3 ). Both the overall and the beat-to-beat HRV decreased by $47-59 \%$ in the $<30$-d-old lambs $(p<0.001$, Table 5). In the older lambs the beat-to-beat HRV did not change, and the CV and CVR decreased less than in the younger lambs (about $20 \%, p<0.05$, Table 5). A difference was found between the age groups in the response of all HRV $(p<$ 0.001 ). Multiple linear regression analysis showed that the proportional changes in RMSM, RMSR, CV, CVR, RMSSD ( $p<$ $0.05)$, and CVS $(p=0.06)$ were positively associated with the age of the animals but not with the mean heart rate (Table 3 ). The changes in CV and CVS were greater than those in RMSM and RMSSD, respectively ( $p<0.001$, Table 5$)$.

In the younger lambs the maximal change in heart rate and HRV caused by propranolol administration did not differ from the mean response (data not shown). In contrast, in the older lambs, the maximal response of all HRV indices showed a more than $20 \%$ rise compared with the mean response: RMSM decreased maximally by $37 \%$ and $\mathrm{CV}$ by $44 \%(p<0.01)$. The reduction in beat-to-beat HRV was insignificant.

Spectral components of HRV . All spectral components of HRV decreased during the 10 -min period of $\beta$-blockade in the $<30$-dold group $(p<0.01$, Fig. $5 A)$. In the older lambs, the reduction was less uniform, although significant, except at the frequency band of $0.5 \mathrm{~Hz}$ (Fig. $5 \mathrm{C}$ ). The respective relative spectral densities in the two subgroups were different. In the younger lambs, the distribution was similar in $\beta$-blockade and in control situations (Fig. $5 B$ ). In the older lambs, propranolol induced a decrease of relative $\mathrm{HRV}$ power at frequencies of $\leq 0.2 \mathrm{~Hz}(<12$ oscillations/ min), and shifted it to $0.3-0.5 \mathrm{~Hz}$ (Fig. $5 D$ ).

Associated with the maximal heart rate reduction during $\beta$ blockade the spectral densities of HRV were similar to the mean responses. In both age groups the relative spectral distribution of the HRV remained unchanged.

\section{DISCUSSION}

Spontaneous oscillations in heart rate are caused by complex nervous control mechanisms adjusting cardiac output to meet the requirements of the peripheral circulation. Three features of the circulatory control mechanism are prerequisites for generating oscillatory $\mathrm{HRV}: l$ ) negative feedback via baroreceptors, 2 ) time delay, and 3) dual efferent nervous control consisting of fast vagal and slower sympathetic pathways $(11,12)$. The vagal system reduces the heart rate and cardiac output with a reaction time of less than $1 \mathrm{~s}$, whereas the sympathetic system increases them, acting in $2-3 \mathrm{~s}$ in adults $(13,14)$. In neonates, the time delay in baroreflex is longer $(12,15)$ and the sensitivity of baroreflex is weaker than in adults (16). There has been controversial information about whether $\mathrm{HRV}$ is, as with the sino-atrial node, under dual autonomic control (17-24). Our results indicate that in young neonatal lambs both divisions of the autonomic nervous system regulate HRV. Concerning the control systems, some questions may arise in relation to the neonatal period, such as the advantage of this dual autonomic control, the roles of the two divisions in development during the postnatal period, and whether disturbed or abnormal autonomic control causes specific patterns in perinatal cardiopulmonary adaptation that could be used for diagnostic or monitoring purposes.

Some earlier studies show that the vagal, but not the $\beta$ adrenergic system, has a regulatory role on HRV in adult humans or animals $(17,18,21)$. Surprisingly few attempts have been made to document the role of the autonomic nervous system in the regulation of HRV in the peri- and postnatal periods, and the results on the role of $\beta$-adrenergic sympathetic division are 

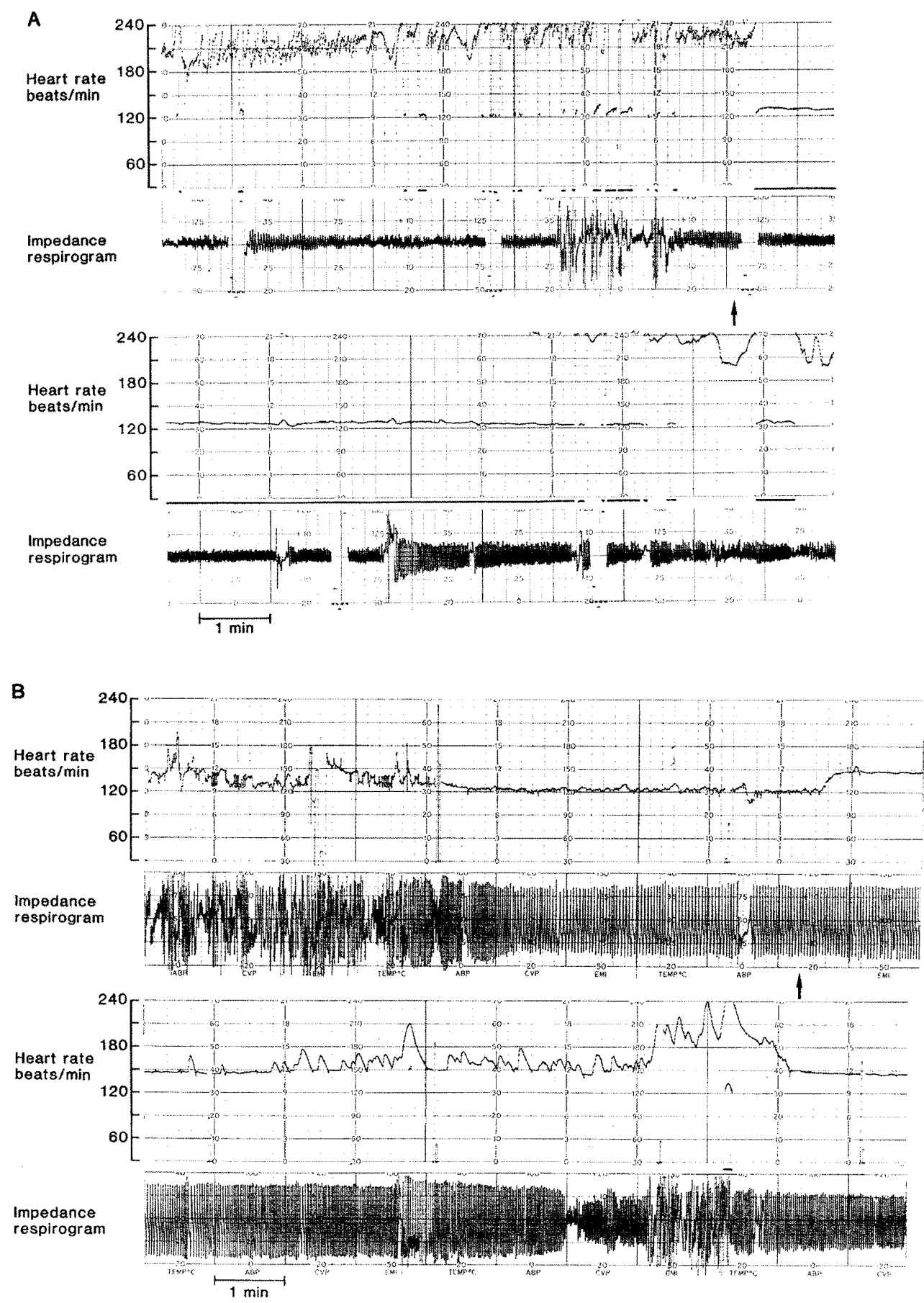

Fig. 2. Original tracings of instantaneous heart rate and respirogram before and after administration of atropine (arrow) at a dose of $0.2 \mathrm{mg} / \mathrm{kg}$ in a 10-d-old lamb $(A)$ and a 36 -d-old lamb $(B)$. Note that in the younger lamb the heart rate rose to 260 bpm after vagal blockade. In the display of the commercial monitor the heart rate readings exceeding $240 \mathrm{bpm}$ (solid line below the heart rate tracing) were automatically scaled to half size.

Table 2. Vagal blockade; multiple regression analysis of responses of heart rate and HRV to age and the mean heart rate or mean $R-R$ interval during vagal blockade

$\Delta$ heart rate $=-1.128^{0.001} \times$ age $-0.258^{0.01} \times$ mean heart rate +109.5
$\Delta \%$ heart rate $=-0.828 \times$ age $-0.333^{0.0001} \times$ mean heart rate +100.6
$\Delta \%$ RMSM $=1.357^{0.05} \times$ age $-0.032^{\mathrm{NS}} \times$ mean R-R interval -65.66
$\Delta \%$ RMSR $=1.373^{0.03} \times$ age $-0.045^{\mathrm{NS}} \times$ mean R-R interval -71.73
$\Delta \% \mathrm{CV}=0.973^{\mathrm{NS}} \times$ age $+0.010^{\mathrm{NS}} \times$ mean R-R interval -62.41
$\Delta \% \mathrm{CVR}=1.369^{0.05} \times$ age $-0.009^{\mathrm{NS}} \times$ mean R-R interval -75.98
$\Delta \% \mathrm{RMSSD}=0.540^{0.08} \times$ age $-0.023^{\mathrm{NS}} \times$ mean R-R interval -84.00
$\Delta \% \mathrm{CVS}=0.390^{\mathrm{NS}} \times$ age $+0.013^{\mathrm{NS}} \times$ mean R-R interval -90.21


Table 3. $\beta$-Blockade; multiple regression analysis of change in heart rate and HRV during $\beta$-blockade related to age, and to mean heart rate

$\Delta$ heart rate $=-0.342^{0.04} \times$ age $-0.477^{0.0001} \times$ mean heart rate +64.58
$\Delta \%$ heart rate $=-0.204^{0.04} \times$ age $-0.201^{0.001} \times$ mean heart rate +25.57
$\Delta \%$ RMSM $=0.988^{0.02} \times$ age $+0.109^{\mathrm{NS}} \times$ mean heart rate -81.24
$\Delta \% \mathrm{RMSR}=0.175^{0.03} \times$ age $+0.023^{\mathrm{NS}} \times$ mean heart rate -15.69
$\Delta \% \mathrm{CV}=0.745^{0.04} \times$ age $-0.040^{\mathrm{NS}} \times$ mean heart rate -58.46
$\Delta \% \mathrm{CVR}=0.756^{0.04} \times$ age $-0.069^{\mathrm{NS}} \times$ mean heart rate -55.86
$\Delta \% \mathrm{RMSSD}=0.226^{0.05} \times$ age $+0.031^{\mathrm{NS}} \times$ mean heart rate -14.54
$\Delta \% \mathrm{CVS}=1.134^{0.06} \times$ age $-0.139^{\mathrm{NS}} \times$ mean heart rate -41.24

Table 4. Absolute and percentage changes in mean heart rate (HR), mean $R-R$ interval $(R R)$, and indices of $H R V$ induced by vagal blockade in lambs less than and more than 30 d old; means \pm SEM

\begin{tabular}{|c|c|c|c|c|c|c|c|c|}
\hline & \multirow[b]{2}{*}{$\begin{array}{c}\text { HR } \\
(1 / \mathrm{min})\end{array}$} & \multirow[b]{2}{*}{$\begin{array}{l}\mathrm{RR} \\
\text { (ms) }\end{array}$} & \multicolumn{4}{|c|}{ Overall HRV } & \multicolumn{2}{|c|}{ Beat-to-beat HRV } \\
\hline & & & $\begin{array}{c}\text { RMSM } \\
(\mathrm{ms})\end{array}$ & $\begin{array}{c}\text { RMSR } \\
(\mathrm{ms})\end{array}$ & $\begin{array}{l}\mathrm{CV} \\
(\%)\end{array}$ & $\begin{array}{l}\text { CVR } \\
(\%)\end{array}$ & $\begin{array}{l}\text { RMSSD } \\
\quad(\mathrm{ms})\end{array}$ & $\begin{array}{l}\text { CVS } \\
(\%)\end{array}$ \\
\hline \multicolumn{9}{|c|}{ Age $<30 \mathrm{~d}(n=20)$} \\
\hline Atropine & $234.2 \pm 9.3$ & $266.9 \pm 13.0$ & $8.2 \pm 0.9$ & $5.4 \pm 0.8$ & $3.00 \pm 0.25$ & $1.95 \pm 0.20$ & $2.2 \pm 0.7$ & $0.80 \pm 0.23$ \\
\hline Control & $187.9 \pm 10.7$ & $345.8 \pm 22.8$ & $18.6 \pm 1.6$ & $16.2 \pm 1.3$ & $5.44 \pm 0.32$ & $4.74 \pm 0.27$ & $13.0 \pm 2.0$ & $3.63 \pm 0.41$ \\
\hline$p$ & $<0.001$ & $<0.001$ & $<0.001$ & $<0.001$ & $<0.001$ & $<0.001$ & $<0.001$ & $<0.001$ \\
\hline \multicolumn{9}{|c|}{ Age $>30 \mathrm{~d}(n=16)$} \\
\hline Atropine & $156.8 \pm 5.4$ & $390.0 \pm 12.8$ & $12.0 \pm 1.8$ & $8.7 \pm 1.4$ & $3.02 \pm 0.41$ & $2.18 \pm 0.32$ & $3.1 \pm 0.5$ & $0.76 \pm 0.10$ \\
\hline Control & $130.1 \pm 4.7$ & $472.2 \pm 17.8$ & $20.5 \pm 2.7$ & $18.2 \pm 2.6$ & $4.24 \pm 0.42$ & $3.73 \pm 0.41$ & $18.4 \pm 3.3$ & $3.70 \pm 0.54$ \\
\hline$p$ & $<0.001$ & $<0.001$ & $<0.016$ & 0.005 & NS & 0.014 & $<0.001$ & $<0.001$ \\
\hline$p^{*}$ & $<0.001$ & $<0.001$ & NS & NS & 0.026 & 0.040 & NS & NS \\
\hline \multicolumn{9}{|l|}{$\%$ change } \\
\hline Age $<30 \mathrm{~d}$ & $28.4 \pm 4.1$ & $-20.9 \pm 2.2$ & $-54.2 \pm 5.5$ & $-65.3 \pm 5.2$ & $-41.0 \pm 7.2$ & $-55.8 \pm 6.2$ & $-83.7 \pm 2.5$ & $-78.4 \pm 4.0$ \\
\hline Age $>30 \mathrm{~d}$ & $20.7 \pm 2.8$ & $-16.9 \pm 1.8$ & $-33.6 \pm 10.9$ & $-38.4 \pm 12.2$ & $-22.3 \pm 12.3$ & $-27.5 \pm 13.8$ & $-73.4 \pm 6.0$ & $-69.4 \pm 6.5$ \\
\hline
\end{tabular}

p* Compared with the control value $<30 \mathrm{~d}$.
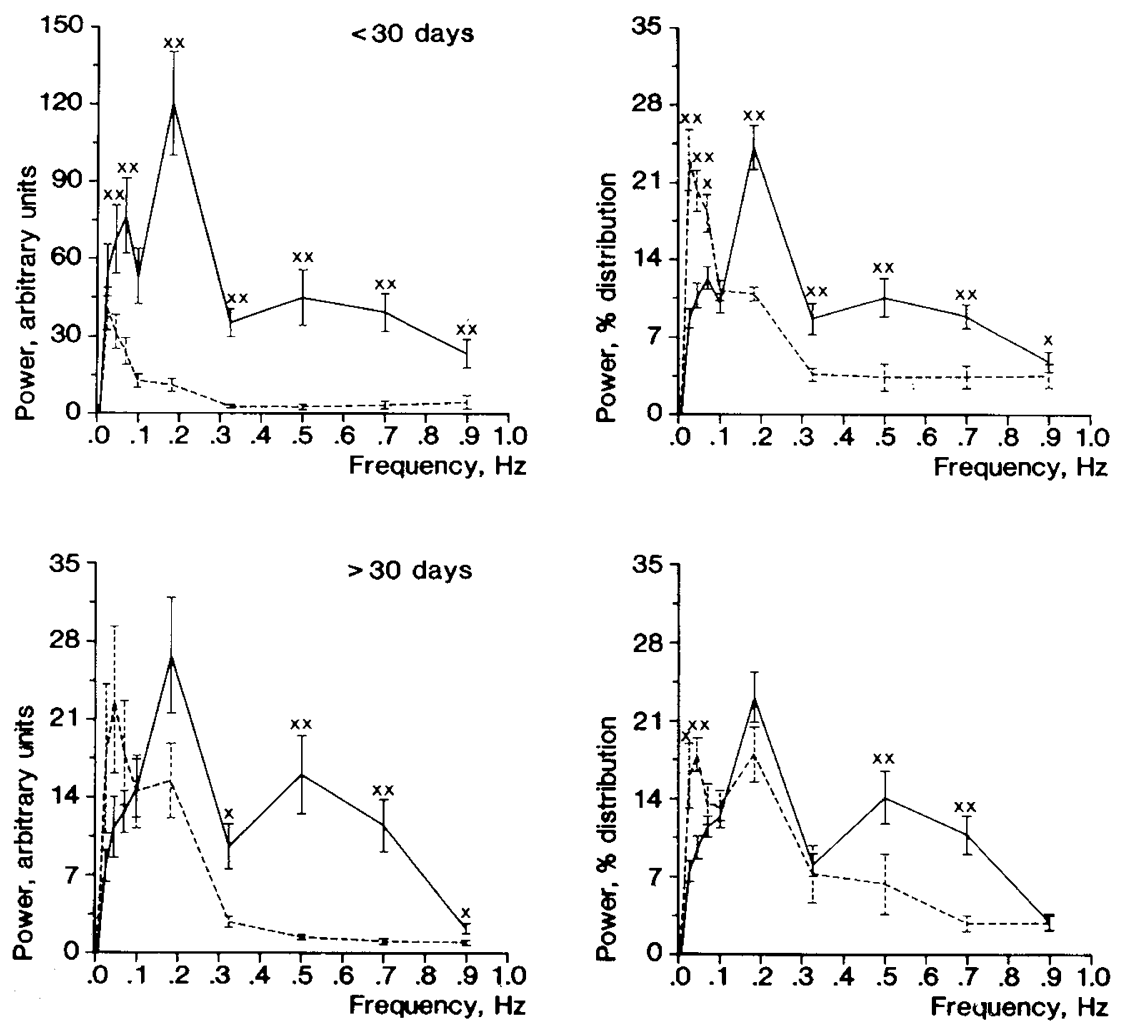

Fig. 3. Band-integrated power spectra of HRV for lambs less than $30 \mathrm{~d}$ old $(n=20)$ computed in arbitrary units ( $A$; left upper) and percentages ( $B$; right upper) and, respectively, for lambs more than $30 \mathrm{~d}$ old $(n=16)(C$; left lower and $D$; right lower) before (solid line) and after vagal blockade (dotted line). Mean + SEM. ${ }^{*} p<0.05,{ }^{* *} p<0.01$. 
A
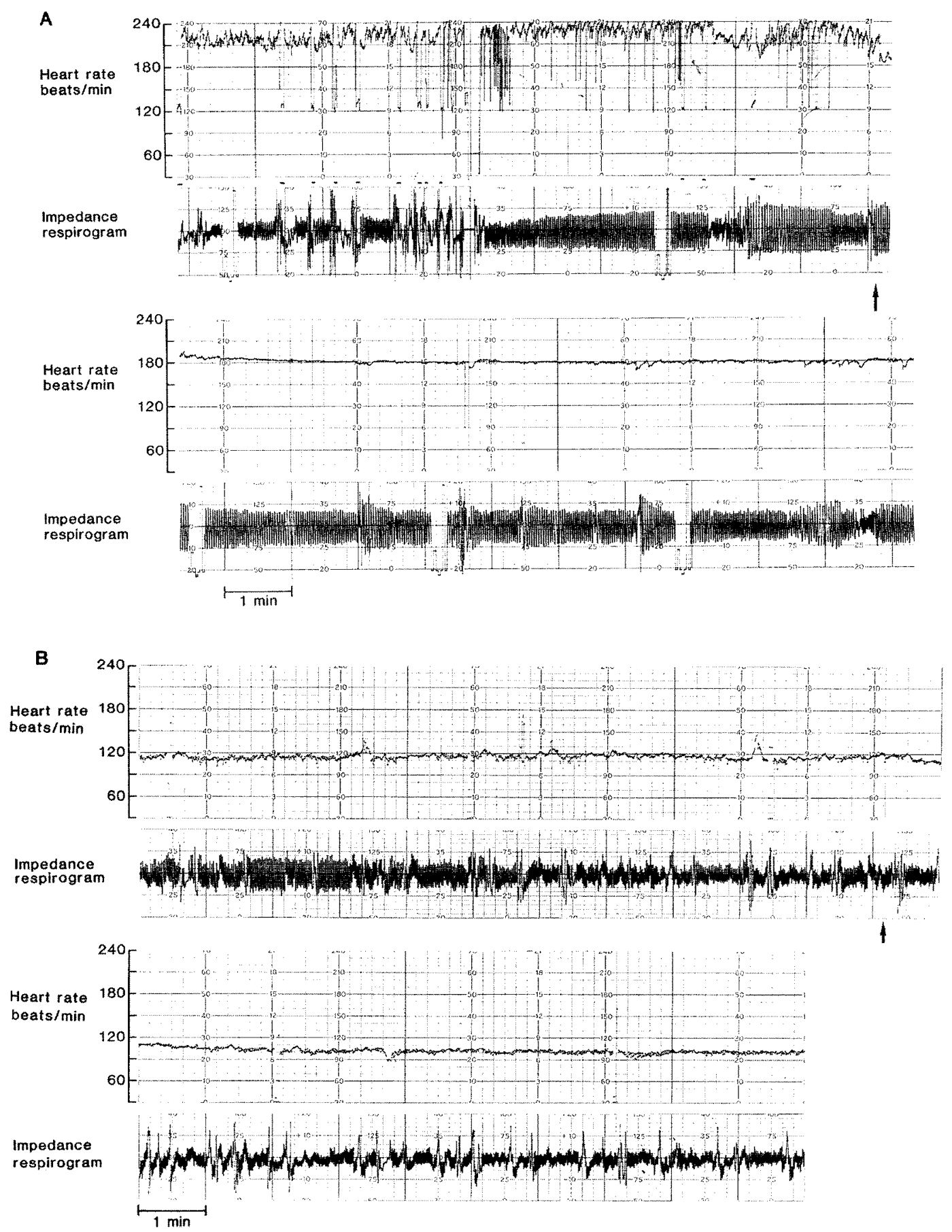

Fig. 4. Tracings of heart rate and respirogram before and after administration of propranolol (arrow) at a dose of $1 \mathrm{mg} / \mathrm{kg}$ in an 8 -d-old lamb $(A)$ and at a dose of $2 \mathrm{mg} / \mathrm{kg}$ in a $67-\mathrm{d}$-old lamb $(B)$. As in Figure 1, the heart rate values exceeding 240 bpm (indicated with a solid line) were automatically scaled to half size by the monitor.

controversial $(20,25)$. In fetal lambs, propranolol administration induced no response, but in neonatal lambs an increasing response of the HRV indices with age was reported. In our study, even though the proportional change in the overall HRV indices after $\beta$-blockade was positively associated with age, all HRV responses were significantly smaller in the older lambs. The HRV indices used by Zugaib et al. (25) may not quantify increasing short-term heart rate irregularities, e.g. oscillations occurring with increasing frequency (26) and, unlike spectral analysis, they do not measure the frequency distribution of HRV. Further, statistical indices are sensitive to transients and trends in the sample of heart beats; they are only rough estimates of the overall and beat-to-beat variability. For these reasons, in addition to HRV indices we used spectral analysis to quantify HRV. We found the method of spectral band integration (8-10) convenient for studying frequency-selective responses to autonomic blockades. We analyzed five bands above and five bands below $0.15 \mathrm{~Hz}$, because several important physiologic mechanisms have been reported to act at low frequencies, including baroreceptor control of blood pressure at $0.1 \mathrm{~Hz}$, vasomotor thermoregulation, and the renin-angiotensin system at $0.04-0.05 \mathrm{~Hz}(10,24,27)$. The high-frequency HRV component $(>0.20 \mathrm{~Hz})$ is influenced only by the respiration, and in neonates even less than in adults (11, $12,27)$. We used a polynomial approximation up to the 4 th order for trend removal in successive 90-s time series. The relatively small change in HRV indices after correction indicates good stationarity of the source time series. We lost data less than $0.02 \mathrm{~Hz}(9)$, but this frequency is not of interest to us. 
Table 5. Respective data as in Table 1 before and after $\beta$-blockade; means \pm SEM

\begin{tabular}{|c|c|c|c|c|c|c|c|c|}
\hline & \multirow[b]{2}{*}{$\begin{array}{c}\text { HR } \\
(1 / \mathrm{min})\end{array}$} & \multirow[b]{2}{*}{$\begin{array}{c}\mathrm{RR} \\
(\mathrm{ms})\end{array}$} & \multicolumn{4}{|c|}{ Overall HRV } & \multicolumn{2}{|c|}{ Beat-to-beat HRV } \\
\hline & & & $\begin{array}{c}\text { RMSM } \\
\text { (ms) }\end{array}$ & $\begin{array}{c}\text { RMSR } \\
\text { (ms) }\end{array}$ & $\begin{array}{l}\mathrm{CV} \\
(\%)\end{array}$ & $\begin{array}{c}\text { CVR } \\
(\%)\end{array}$ & $\begin{array}{l}\text { RMSSD } \\
\quad(\mathrm{ms})\end{array}$ & $\begin{array}{c}\text { CVS } \\
(\%)\end{array}$ \\
\hline \multicolumn{9}{|c|}{ Age $<30 \mathrm{~d}(n=14)$} \\
\hline Propranolol & $157.2 \pm 6.3$ & $391.0 \pm 17.0$ & $9.3 \pm 1.0$ & $7.5 \pm 0.8$ & $2.44 \pm 0.32$ & $1.97 \pm 0.25$ & $4.9 \pm 0.6$ & $1.27 \pm 0.15$ \\
\hline Control & $188.1 \pm 9.0$ & $330.2 \pm 18.1$ & $17.4 \pm 0.89$ & $15.1 \pm 0.8$ & $5.47 \pm 0.42$ & $4.73 \pm 0.36$ & $9.9 \pm 0.5$ & $3.10 \pm 0.24$ \\
\hline$p$ & $<0.001$ & $<0.001$ & $<0.001$ & $<0.001$ & $<0.001$ & $<0.001$ & $<0.001$ & $<0.001$ \\
\hline \multicolumn{9}{|c|}{ Age $>30 \mathrm{~d}(n=12)$} \\
\hline Propranolol & $111.5 \pm 4.0$ & $547.0 \pm 19.0$ & $18.0 \pm 3.7$ & $15.9 \pm 3.8$ & $3.17 \pm 0.58$ & $2.79 \pm 0.60$ & $18.9 \pm 5.7$ & $3.25 \pm 0.93$ \\
\hline Control & $123.6 \pm 4.2$ & $493.0 \pm 16.5$ & $20.6 \pm 4.3$ & $17.9 \pm 4.4$ & $4.15 \pm 0.86$ & $3.60 \pm 0.89$ & $18.0 \pm 7.1$ & $3.54 \pm 1.41$ \\
\hline$p$ & $<0.001$ & $<0.001$ & NS & NS & 0.031 & 0.065 & NS & NS \\
\hline$p^{*}$ & $<0.001$ & $<0.001$ & NS & NS & $<0.01$ & $<0.01$ & NS & NS \\
\hline \multicolumn{9}{|l|}{$\%$ change } \\
\hline Age $<30 \mathrm{~d}$ & $-15.8 \pm 1.9$ & $19.8 \pm 2.8$ & $-47.3 \pm 4.8$ & $-50.7 \pm 4.6$ & $-56.6 \pm 3.7$ & $-58.9 \pm 3.6$ & $-51.5 \pm 5.8$ & $-54.5 \pm 5.8$ \\
\hline Age $>30 d$ & $-9.6 \pm 1.4$ & $10.9 \pm 1.7$ & $-12.0 \pm 6.6$ & $-5.9 \pm 7.1$ & $-20.7 \pm 6.1$ & $-23.1 \pm 7.1$ & $17.3 \pm 10.6$ & $-8.5 \pm 10.0$ \\
\hline$p$ & 0.019 & 0.014 & $<0.001$ & $<0.001$ & $<0.001$ & $<0.001$ & $<0.001$ & $<0.001$ \\
\hline
\end{tabular}

$p^{*}$ As in Table 1 .
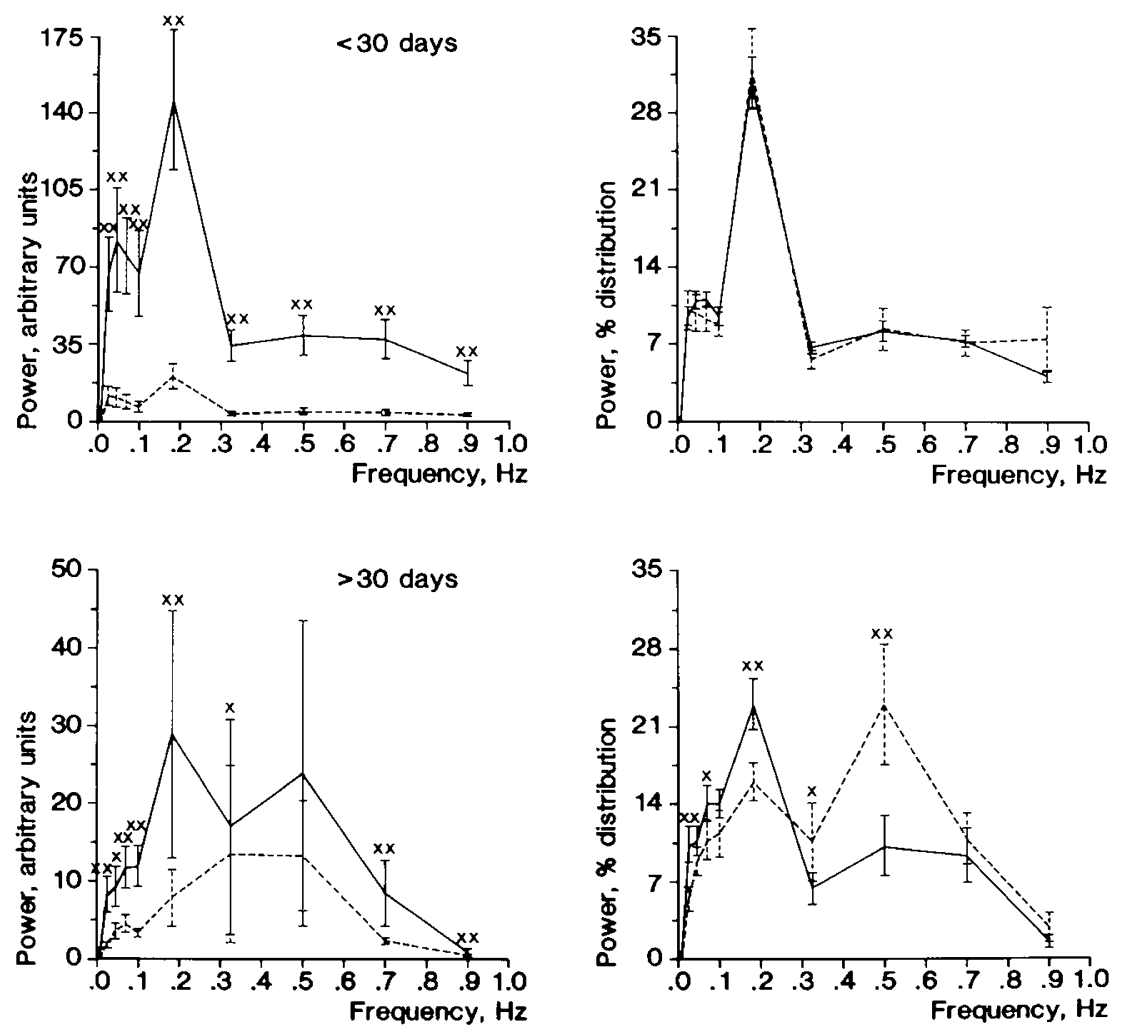

Fig. 5. Band-integrated power spectra of HRV for lambs less than $30 \mathrm{~d}$ old $(n=14)$ in arbitrary units $(A ;$ left upper $)$ and percentages $(B$; right upper), and, respectively, for lambs more than $30 \mathrm{~d}$ old $(n=12)(C$; left lower and $D$; right lower) before (solid line) and after $\beta$-blockade (dotted line). Mean + SEM. $*$ and ${ }^{* *}$ as in Figure 3.

It appears that in neonatal lambs, the vagal division has a stronger influence on HRV than the sympathetic division, in particular affecting the rapid changes in heart rate. The $\beta$ adrenergic system, however, seemed to account for half of the total variability measured by the HRV indices after birth and without any frequency selection. These results differ from earlier findings in adult man, dog, and cat; in these the high-frequency HRV was found to be only under vagal control, whereas the $\beta$ adrenergic division showed its effect only on the low-frequency HRV, and even then in situations with high adrenergic tone (17$19,21-23)$. In our study, the different response times of the two autonomic systems were more evident in the older lambs than in younger animals. Even so, the $\beta$-adrenergic system showed some effect on the slow changes of heart rate, whereas the vagal system affected not only the rapid changes, but also, although less strongly, the slow ones. Vagal blockade also shifted the relative HRV power from higher to lower frequencies. This indicates that the control system became unstable and may have started to oscillate, which was in fact demonstrated in the heart rate tracings as slow accelerations at a rate of one to five cycles per min in all lambs (Figs. 2 and 3). This phenomenon may be related to a reciprocal increase in sympathetic nervous system activity or in plasma vasopressin concentration $(28,29)$, because a sinusoidal heart rate curve has been experimentally produced by vasopressin infusion into fetal lambs during vagal blockade (30). Reacting rapidly, the vagal system induces high-frequency 
components of HRV, but it also seems to damp slow sinusoidal accelerations of the heart rate. The tendency of the indices RMSM, RMSR, and RMSSD to increase with declining heart rate, and vice versa, also reported earlier $(31,32)$, may mask the effect of $\beta$-blockade on HRV during bradycardia, or the effect of atropine may be visually overestimated. This problem should be avoided by using HRV indices properly corrected for the length of the R-R intervals, in this study CV. CVR, and CVS, although not in visual HRV estimations of the clinical heart rate tracings. Therefore, for comparison, we also wished to show uncorrected indices such as RMSM, RMSR, and RMSSD

The impact of the sympathetic system on heart rate decreased with age, but its influence on the HRV did so even more strongly. The development of vagal predominance with age, but a high $\beta$ adrenergic state in lambs during the first few weeks of life, as evidenced by the response of the heart rate to propranolol (25, 33,34 ), also found here, may explain why propranolol had a greater effect on HRV in the younger lambs than in the older lambs or fetal lambs (20). Our study does not exclude either myocardial depression induced by administration of propranolol to immature animals, as described in puppies, kittens, and lambs $(35,36)$, or a possible central inhibitory effect of propranolol. If the peripheral resistance of the vasculature operates as a lowpass filter (12) and the filtering effect of the peripheral sympathetic tone declines with age, the high-frequency irregularity in the heart rate may increase (8). The postnatal maturation of the control of the central circulation, cardiac output, and peripheral vasculature, as well as developmental changes in the sinus node itself $(11,16,36)$, may also contribute to changes in heart rate and HRV. Thus, during the neonatal period the autonomic nervous control of the heart is modified by the development of both regulatory and effector organs.

In man, the normal development of heart rate control may be seriously affected by several perinatally occurring diseases. Although perinatal asphyxia and depression of the CNS in respiratory distress syndrome and brain death may result in a flat heart rate curve, our present and earlier findings in lambs indicate that blocking autonomic control may reduce neonatal HRV by $80-90 \%$ without causing any changes in the arterial $\mathrm{pH}$ or gas tensions (9). In human neonates however, a negative correlation has been found between the $\mathrm{PCO}_{2}$ and $\mathrm{HRV}$ (37). Abnormal development of autonomic nervous control of autonomic imbalance in the neonate during an acute illness and convalescence may produce clinically useful diagnostic patterns of heart rate. Our results suggest that in vagal failure a sinusoidal heart rate pattern may appear, a flat curve after suppression of the entire autonomic nervous system, or increased HRV may result from its stimulation in neonatal lambs. Further information is needed on human neonates, especially, because both atropine and propranolol are clinically used drugs.

In lambs, the most important mechanism regulating HRV after birth seems to be the dual autonomic nervous control with vagal dominance, and this mechanism is needed to ensure adequate stability of the heart rate during early cardiovascular adaptation. With age, the decrease in direct autonomic control of HRV is followed by accentuation of specific frequency selections of its two divisions.

Acknowledgment. The Corometrics Neonatal Monitor was placed at our disposal by the Kone Corporation, Instrument Division, Espoo, Finland.

\section{REFERENCES}

1. Kero P 1974 Heart-rate variation in infants with the respiratory distress syndrome. Acta Paediatr Scand [Suppl]250:1-70

2. Äärimaa T, Oja R, Antila K, Välimäki I 1988 Interaction of heart rate and respiration in newborn babies. Pediatr Res 24:745-750

3. Anttila H 1989 Analysis of Neonatal Heart Rate Variability. Thesis, University of Turku, Annales Universitatis Turkuensis, Ser. D, N:0 37

4. Kero P, Antila K, Ylitalo V, Välimäki I 1978 Decreased heart rate variation in decerebration syndrome: quantitative clinical criterion of brain death? Pediatrics 62:307-311

5. Divon MY, Winker H, Yeh S-Y, Platt LD, Langer O, Merkatz IR 1986 Diminished respiratory sinus arrhythmia in asphyxiated term infants. Am J Obstet Gynecol 155:1263-1266

6. Kluge KA, Harper RM, Schechtman VL, Wilson AJ, Hoffman HJ, Southall DP 1988 Spectral analysis assessment of respiratory sinus arrhythmia in normal infants and infants who subsequently died of sudden infant death syndrome. Pediatr Res 24:677-682

7. Harper RM, Hoppenbrouwers T, Sterman MB, McGinty DJ, Hodgman JE 1976 Polygraphic studies of normal infants during the first six months of life. I. Heart rate variability as a function of a state. Pediatr Res 10:945-951

8. Siimes ASI, Välimäki IAT, Sarajas HSS, Sakoné K, Oja RT 1984 Heart rate variation in relation to age and sleep state in neonatal lambs. Acta Physiol Scand [Suppl]537:7-15

9. Siimes ASI, Välimäki IAT, Oja RT, Antila KJ 1986 Detection of components of autonomic cardiac control by time series analysis of heart rate in lambs. Technical report. In: Fetal Physiological Measurements, Rolfe P (ed), Butterworths, London, pp 259-266

10. Lindqvist A, Oja R, Hellman O, Välimäki I 1983 Impact of thermal vasomotor control on the heart rate variability of newborn infants. Early Hum Dev $8: 37-47$

11. McDonald AH 1980 Mechanisms affecting heart-rate. In: Kitney RI, Rompelman O (eds) The Study of Heart-Rate Variability. Clarendon Press, Oxford, pp 3-12

12. Giddens DP, Kitney RI 1985 Neonatal heart rate variability and its relation to respiration. J Theor Biol 113:759-780

13. Koizumi K, Terui N, Kollai M 1985 Effect of cardiac vagal and sympathetic nerve activity on heart rate in rhythmic fluctuations. J Auton Nerv Syst $12: 251-259$

14. Warner HR, Russell Jr RO 1969 Effect of combined sympathetic and vagal stimulation on heart rate in the dog. Circ Res 24:567-573

15. Grönlund JU, Antila KJ, Siimes ASI, Metsälä T, Oja R, Tuominen J, Välimäki IAT 1989 Beta-adrenergic control and inter-relationships between heart rate and blood pressure in neonatal lambs. Med Biol Eng Comput 27:163-170

16. Blanco CE, Dawes GS, Hanson MA, McCooke HB 1988 Carotid baroreceptors in fetal and newborn sheep. Pediatr Res 24:342-346

17. Hamlin RL, Smith CR, Smetzer DL 1966 Sinus arrhythmia in the dog. Am J Physiol 210:321-328

18. Chess GF, Tam RMK, Calaresu FR 1975 Influence of cardiac neural inputs on rhythmic variations of heart period in the cat. Am J Physiol 228:775780

19. McCabe PM, Yongue BG, Ackles PK, Porges SW 1985 Changes in heart period, heart period-variability, and a spectral analysis estimate of respiratory sinus arrhytmia in response to pharmacological manipulations of the baroreflex in cats.Psychophysiology 22:195-203

20. Dalton KJ, Dawes GS, Patrick JE 1983 The autonomic nervous system and fetal heart rate variability. Am J Obstet Gynecol 146:456-462

21. Coker R, Koziell A, Oliver C, Smith SE 1984 Does the sympathetic nervous system influence sinus arrhythmia in man? Evidence from combined autonomic blockade. J Physiol 356:459-464

22. Pagani M, Lombardi F, Guzzetti S, Sandrone G, Rimoldi O. Malfatto G, Cerutti S, Malliani A 1984 Power spectral density of heart rate variability as an index of sympatho-vagal interaction in normal and hypertensive subjects. J Hypertens 2(suppl 3):383-385

23. Pomeranz B, Macaulay RJB, Caudill MA, Kutz I, Adam D, Gordon D, Kilborn KM, Barger AC, Shannon DC, Cohen RJ, Benson H 1985 Assessment of autonomic function in humans by heart rate spectral analysis. Am $\mathrm{J}$ Physiol 248:H151-H153

24. Akselrod S, Gordon D, Ubel FA, Shannon DC, Barger AC, Cohen RJ 198 Power spectrum analysis of heart rate fluctuation: a quantitative probe of beat-to-beat cardiovascular control. Science 213:220-222

25. Zugaib M, Forsythe AB, Nuwayhid B, Lieb SM, Tabsh K, Erkkola R, Ushioda E, Brinkman III CR, Assali NS 1980 Mechanisms of beat-to-beat variability in the heart rate of the neonatal lamb. I. Influence of the autonomic nervous system. Am J Obstet Gynecol 138:444-452

26. Parer WJ, Parer JT, Holbrook RH, Block BSB 1985 Validity of mathematical methods of quantitating fetal heart rate variability. Am J Obstet Gynecol 153:402-409

27. Sayers BMcA 1973 Analysis of heart rate variability. Ergonomics 16:17-32

28. Kollai M, Koizumi K 1979 Reciprocal and non-reciprocal action of the vagal and sympathetic nerves innervating the heart. J Auton Nerv Syst 1:33-52

29. Hasser EM, Haywood JR, Johnson AK, Bishop VS 1984 The role of vasopres$\sin$ and the sympathetic nervous system in the cardiovascular response to vagal cold block in the conscious dog. Circ Res 55:454-462

30. Murata Y, Miyake Y, Yamamoto T, Higuchi M, Hesser J, Ibara S, Bessho T, Tyner JG 1985 Experimentally produced sinusoidal fetal heart rate patterns in the chronically instrumented fetal lamb. Am J Obstet Gynecol 153:693702

31. Siimes ASI, Oja RT, Välimäki IAT 1985 Should heart-rate variability be computed using heart-beat interval or heart-rate scale? Comparison of data during autonomic blockade in neonatal lambs. Med Biol Eng Comp 23(suppl part I):319-320

32. Sigurd J, Löfgren O, Joelsson I 1985 Cardiotocographic distortion of fetal heart rate variability. Acta Obstet Gynecol 64:255-258

33. Woods Jr JR, Dandavino A, Murayama K, Brinkman III CR, Assali NS 1977 
Autonomic control of cardiovascular functions during neonatal development and in adult sheep. Circ Res 40:401-407

34. Teitel DF, Sidi D, Chin T, Brett C, Heymann MA, Rudolph AM 1985 Developmental changes in myocardial contractile reserve in the lamb. Pediatr Res 19:948-955

35. Truccone NJ, Spontnitz HM, Gersony WM 1976 Comparative cardiovascular effects of propranolol and practolol in puppies. Proc Soc Exp Biol Med 151:351-355

36. Gootman PM, Gootman N, Turlapaty PDMV, Yao AC, Buckley BJ, Altura
BM 1981 Autonomic regulation of cardiovascular function in neonates. In: Development of the Autonomic Nervous System. Pitman Medical, London (Ciba Foundation symposium 83), pp 70-93

37. Äärimaa T, Kero P, Välimäki I 1985 Simultaneous monitoring of transcutaneous blood gases and heart-rate variation in neonates. Crit Care Med 13:911

38. Siimes ASI, Karhi TH, Antila KJ, Oja RT, Halttunen M, Halkola L, Luosto T, Sakoné K, Sarajas HSS, Välimäki IAT 1983 Adrenergic and cholinergic control of heart rate variation in newborn lambs. Clin Physiol 3 (suppl 2):56 